\title{
A design theory for digital platforms supporting online communities: a multiple case study
}

\author{
Paolo Spagnoletti ${ }^{1}$, Andrea Resca ${ }^{2}$, Gwanhoo Lee $^{3}$ \\ ${ }^{1}$ Department of Business and Management - LUISS Guido Carli University, Roma, Italy; \\ ${ }^{2}$ Research Center on Information Systems - LUISS Guido Carli University, Roma, Italy; \\ ${ }^{3}$ Kogod School of Business, American University, Washington DC, USA
}

\section{Correspondence:}

P Spagnoletti, Research Center on Information Systems, LUISS Guido Carli University, Via T. Salvini 2, Roma 00197, Italy.

Tel: +39 0685225795;

Fax: +39 06844078510;

E-mail: pspagnoletti@luiss.it

†This research has been partially supported by the European Commission AAL-2009-2-031.

\begin{abstract}
This research proposes and validates a design theory for digital platforms that support online communities (DPsOC). It addresses ways in which digital platforms can effectively support social interactions in online communities. Drawing upon prior literature on IS design theory, online communities, and platforms, we derive an initial set of propositions for designing effective DPsOC. Our overarching proposition is that three components of digital platform architecture (core, interface, and complements) should collectively support the mix of the three distinct types of social interaction structures of online community (information sharing, collaboration, and collective action). We validate the initial propositions and generate additional insights by conducting an in-depth analysis of an European digital platform for elderly care assistance. We further validate the propositions by analyzing three widely used digital platforms, including Twitter, Wikipedia, and Liquidfeedback, and we derive additional propositions and insights that can guide DPsOC design. We discuss the implications of this research for research and practice.

Journal of Information Technology (2015) 30, 364-380. doi:10.1057/jit.2014.37;

published online 10 February 2015

Keywords: design theory; online community; digital platform; platform architecture; design principles; multiple case study
\end{abstract}

The online version of this article is available Open Access

\section{Introduction}

D igital platforms play a crucial role in enabling and sustaining online communities. A platform is a building block that provides an essential function to a technological system and serves as a foundation upon which complementary products, technologies, or services can be developed (Gawer, 2009). While platforms have become important for product and technology development in a wide range of industries, the recent pervasive penetration of digital technology has significantly elevated the importance of platforms especially in IT-enabled products and services (Yoo et al., 2012). Digital platforms differ from applications in that their design context is subject to a wide range of change, because of their heterogeneous, growing user base and the constant addition of new IT capabilities and complements (Williams and Pollock, 2008; Hanseth and Lyytinen, 2010). As such, platform designs draw upon principles that address a family of generic functional requirements that meet the needs of multiple, heterogeneous user communities (Evans et al., 2006). Architecture plays a central role in platform design. Considering the increasing importance of online communities and the crucial role of digital platforms in enabling and sustaining them, organizations need to identify effective design principles for digital platforms supporting online communities (DPsOC).

Although the extant body of knowledge on online communities is useful for explaining and predicting online community behavior and dynamics (Butler et al., 2015), we have little understanding of how organizations can effectively design DPsOC (Stockdale and Borovicka, 2006; Gawer, 2009). The availability of a large amount of data on community members' behavior has allowed researchers to build and test behavioral 
or economic theories of online communities. However, these theories do not address the problems that arise from designing digital platforms that support online social interactions. Therefore, we lack a design theory for such digital platforms; existing design theories for traditional information systems do not adequately take into account the social and interactive processes that take place in online communities (Walls et al., 1992; Huysman and Wulf, 2005). Practitioners are not guided by valid, reliable design principles when designing DPsOC and this may have a negative impact on the sustainability of online communities.

The objective of this study is to develop a design theory for DPsOC by generating and validating a set of propositions that would guide effective design of digital platforms. Drawing from prior literature on IS design theory, online communities, and platforms, we present a conceptual framework that defines important elements of our design theory and guides the process of generating and validating the theory. We define and expound the justificatory knowledge, purpose and scope, and principles of form and function of DPsOC, and derive an initial set of propositions for designing effective DPsOC.

Using a two-phase multiple case study approach (Yin, 2009), we first validate the initial propositions and generate additional insights based on an in-depth analysis of a European digital platform for elderly care assistance. We then further validate the propositions and derive additional propositions by analyzing three widely used digital platforms, composed of Twitter, Wikipedia, and Liquidfeedback. Our study contributes to research and practice by identifying and validating useful principles for designing digital platforms supporting generative, sustainable online communities.

\section{The design theory framework for digital platforms supporting online communities}

Among different types of theories in information systems (Gregor, 2006), prior research on online communities has mainly contributed to four types of theories: theories for analyzing (Stanoevska-Slabeva and Schmid, 2001), theories for explaining (Jones and Rafaeli, 2000), theories for predicting (Rothaermel and Sugiyama, 2001), and theories for explaining and predicting (Balasubramanian and Mahajan, 2001). Few prior studies fall into the tradition of theories for 'design and action,' which focus on building knowledge through the design and evaluation of IT artifacts (Hevner et al., 2004). Theories for design and action differ from descriptive or predictive theories in that they provide explicit prescriptions on how to design and develop an artifact (Simon, 1996; Gregor, 2006).

Our literature review indicates that few design theories have been developed for platforms that support online communities. Given the pervasiveness and increasing importance of online communities, there are compelling needs for such design theories. To fill this gap, building upon Gregor and Jones (2007) and the literature on online communities and platforms, we propose a framework guiding the development of a design theory of DPsOC (Figure 1). The framework consists of four meta-level constructs (testable propositions, justificatory knowledge, purpose and scope, and principles of form and function) and expository instantiation. The proposed framework also shows how the meta-level constructs are related to one another, how they are projected in the expository instantiation of the theory through implementation, and how they are informed by expository instantiation.

Although some studies in the design science research tradition view IT artifacts as the main outcome (March and Smith, 1995; Hevner et al., 2004), other studies emphasize the central role of design theories in the form of testable propositions (Fischer et al., 2010), both as the justificatory knowledge that informs the artifact construction and as the natural outcome of a design research effort (Gregor and Jones, 2007; Baskerville and Pries-Heje, 2010). A testable proposition refers to a 'technological rule' (van Aken, 2004) that links the characteristics of the artifact with a desired outcome under certain environmental conditions. The bridging role of justificatory knowledge has been conceptualized as an essential element for linking the purpose and scope of an artifact with its principles of form and function (Spagnoletti and Tarantino, 2012). Justificatory knowledge is a fundamental tool for providing the researcher with a palette of situated design and evaluation strategies through a better understanding of complex situated phenomena.

The purpose and scope of a design theory is characterized by environmental requirements such as capabilities and conditions that are linked to the principles of form and function of the artifact. These requirements justify the reasons for the presence of the components of an artifact. The purpose and scope embeds artifact mutability or changeability. In this view, justificatory knowledge is a source for analytical, explanatory, predictive, and prescriptive theories, thereby informing the purpose and scope as well as the abstract architecture of the IT artifact. This body of knowledge receives feedbacks from the other components of the framework in the form of testable propositions.

An expository instantiation substantiates a meta-level design theory in a particular empirical setting (Gregor and Jones, 2007). Unlike theories in the natural sciences that are traditionally represented by language or mathematics, the artifact itself has representational and communicative power (Gregor and Jones, 2007). The description of an artifact can communicate the design principles of a theory by outlining the artifact's feasibility, applicability, and usefulness at build time as well as at run time (Sonnenberg and vom Brocke, 2012). This process, called projection, plays a fundamental role in validating the theory in specific contexts (Pries-Heje and Baskerville, 2010).

\section{Theoretical background}

\section{From offline to online communities}

A community is seen as an organic totality in which existing relationships are typified by feelings of togetherness and mutual bonds (Tonnies, 1955). The study of traditional communities suggests that face-to-face relationships mediated by synchronous communication means are the foundation of the communities. However, the development of IT has allowed the proliferation of modalities by which virtual interpersonal relationships can be mediated both through synchronous and asynchronous means of communication.

According to the neoclassical economic view, rational and self-interested individuals do not act to achieve common interests, since self-interests prevail against common interests (Olson, 1971). As a result, the free-riding problem arises. The 


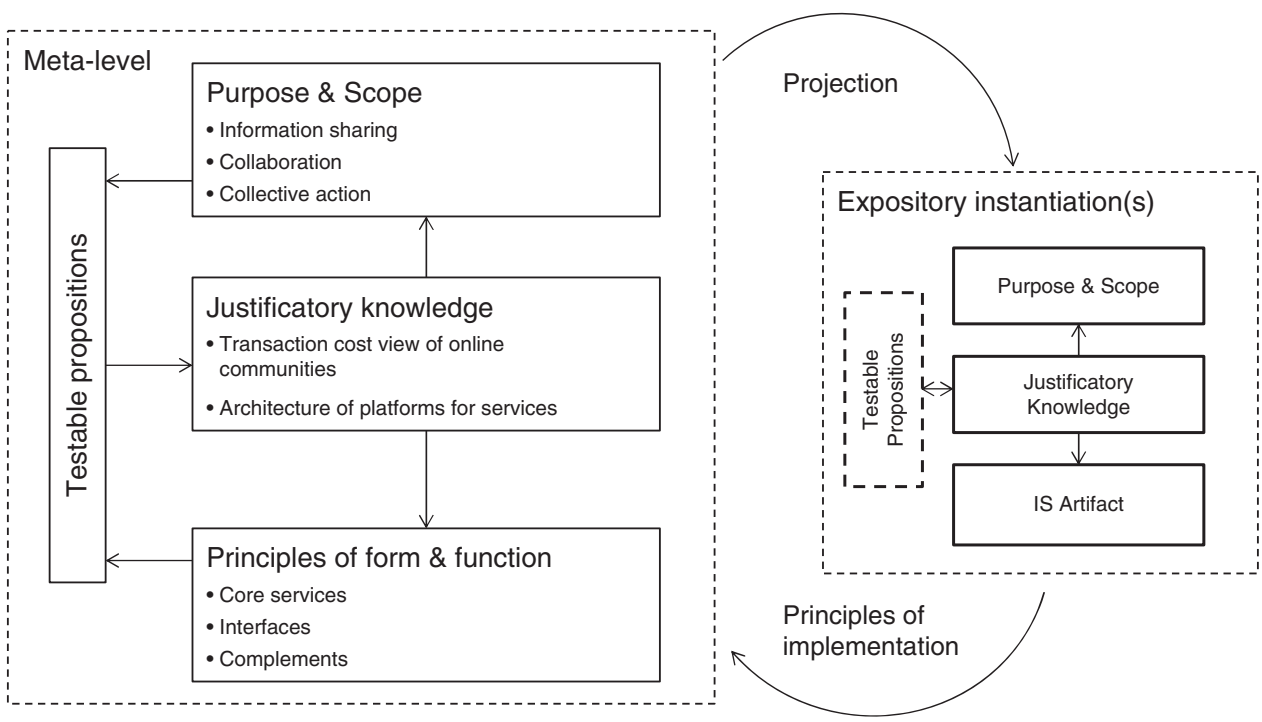

Figure 1 The design theory framework for digital platforms supporting online communities.

solutions to this problem include the presence of an external authority and the privatization of public goods through assigning property rights to each individual. Ostrom (1990, 2000) investigates these solutions and suggests that neither is optimal and that communities can envisage collective actions to prevent the free-riding phenomenon.

According to the transaction cost theory (Coase, 1937; Williamson, 1975, 1985), transactions including social interactions can be governed not only through bureaucracy (external authority) and market (the passage from public goods to private goods) but also by clan (Ouchi, 1980; Wilkins and Ouchi, 1983). In this view, a set of general assumptions and values enables the members involved in social interactions to identify the interests of their community and recognize that those community interests overlap with their personal interests. In online communities, the free-riding problem is kept under control in part because it is impossible to impose property rights. Besides, coordination occurs through self-organizing rather than through authority or price. Members' motivation, character, disposition, and willingness coupled with spontaneity and intangible incentives are the basis of participation in this type of interactions (Benkler, 2002, 2006; Demil and Lecocq, 2006; Tapscott and Williams, 2008).

The transaction cost theory can shed a light on a particular aspect of online communities, namely, social interaction structure that links individuals to collective arrangements (Ciborra, 1996; Resca, 2006; Kallinikos, 2011). Based on the transaction cost theory, Shirky (2008) views the social interactions in the virtual world as populated not only by collaboration (i.e., peer production) but also by information sharing and collective action. These three distinct structures provide a basis for developing the purpose and scope and the principles of form and function of DPsOC (Pradhan and Odugbemi, 2011; Obar et al., 2012).

Platform architecture: core, complement, and interface

Early works on platforms focused on physical product platforms. More recently, however, the conception and theory of physical product platforms have been extended to platforms of software-based products and services (Gawer, 2009; Tiwana et al., 2010). The recent pervasive penetration of digital technology has significantly elevated the importance of a platform of digital capabilities (Yoo et al., 2012). Architecture plays an important role in organizing a growing set of core components, complements, and interfaces into a relatively well-bounded and controlled system (Hanseth and Lyytinen, 2010). The architecture of a product is defined as the scheme by which the function of the product is allocated to physical components (Ulrich, 1995). A platform-based system is a special type of a modular system that is partitioned into a set of relatively stable core components with low variety, a set of evolving peripheral complements with high variety, and a set of interfaces linking core components and complements (Baldwin and Woodard, 2009).

An important property of platform-based systems is that they are evolvable in an ecosystem in which heterogeneous actors are engaged, as they adapt to unanticipated changes in the external environment (Baldwin and Woodard, 2009). Platforms differ from specific products, services, or applications in that their design context is subject to a wide range of change (Williams and Pollock, 2008; Hanseth and Lyytinen, 2010). Platforms grow in complexity as designers accommodate heterogeneous user needs while maintaining backward compatibility and horizontal compatibility across different components. Therefore, platforms often obtain emergent features and serve unexpected user communities, resulting in growing technical and social complexity (Hanseth and Lyytinen, 2010).

Modularity, when combined with standard interfaces, allows for the product or service to evolve and change through independent actions by individual actors (Langlois and Robertson, 1992). Much of the ability to create variety resides with the architecture of the platform system. A modular architecture, as opposed to a tightly-coupled architecture, allows for a one-to-one mapping from elements in the function structure to the physical components of the product, and specifies de-coupled interfaces between components. When the concept of platform is applied to an IT system, the unique material characteristics of digital technology make the 
logic of generativity prevail on the logic of modularity (Yoo, 2013). A digital platform exhibits a layered modular architecture in which elementary IT capabilities are grouped into software applications that are combined to satisfy generic functional specifications that meet the needs of multiple, heterogeneous, and growing user communities (Williams and Pollock, 2008; Hanseth and Lyytinen, 2010; Yoo et al., 2010). Therefore, platform designs draw upon principles that allow for addressing a family of generic functional requirements (Evans et al., 2006).

\section{Supporting online communities through digital platforms: a conceptual analysis}

Social interaction structures of online communities

Social interaction is at the heart of an online community. As such, when designing DPsOC, it is important to understand the dynamics of different types of social interaction structure taking place in online communities. The transaction cost theory is a useful lens to analyze different social interaction structures and their corresponding governance structures. Benkler (2006) and Shirky (2008) suggest that, because of the development of IT, transaction costs collapsed, giving chance to the emergence of new social interaction structures that can be characterized by information sharing, collaboration, and collective action. In this research, we define these three distinct types of social interaction structures as follows:

\section{Information sharing}

Actors make available their own contents on the net, creating a resource available to all. This social interaction structure allows free participation. The essential element is the spontaneous action of the actor, and no form of collaboration is required. What emerges is an aggregation of individuals who perform similar tasks independently. No formal rule or governance mechanism is necessary. The Twitter platform is a classic example.

\section{Collaboration}

Actors follow rules and engage in activities that require substantial group coordination. Participants are required to adapt their behavior to others in order to have a group identity. Collaboration is considered a more complex social interaction structure than information sharing, as it requires a greater alignment between the objective of the group and the objective of the individual. To obtain meaningful results, the participation of a considerable number of actors may be necessary and personal appropriation of such results is not possible in this structure. In contrast to the information sharing structure, it is imperative to coordinate the collaborative behavior through governance mechanisms such as hierarchy and formal rules. Wikipedia and open source software are classic examples of collaborative production.

\section{Collective action}

Actors follow a common goal and abide by common rules established by group membership. It represents a social interaction structure in which regulations are complex and a close coordination is required. Decisions made by group members prevail over personal interests. A strong internal cohesion typifies collective action so that the individual may identify herself with this social unit. While collaboration tends to focus on completing a task through division of labor and coordination among actors, collective action tends to focus on reaching a consensus, making a collective decision, and acting as a group with shared values and trust. Good examples are the applications of e-participation adopted by social movements, political parties, and governments.

These three social interaction structures represent stylized forms taking place in online communities and could be thought of as emerging in comparison with conventional forms, such as markets, bureaucracies, and clans. We argue that digital platforms need to be designed to meet the different requirements of these three structures. To further understand these structures, we compare their characteristics based on the dimensions proposed by Ciborra (1996) and Boisot (1995). Table 1 summarizes the result.

Assuming that the sustainability of an online community lies in part with the characteristics of the digital platform supporting members' interactions, we start from these social interaction structures to identify the capabilities to be met and the conditions to be enforced by the platform. Here, informational requirements play an important role. Their conception according to three continuums (codified/uncodified, concrete/abstract, diffused/undiffused) largely determines the outlining of capabilities and conditions (Boisot and Child, 1999). On the basis of the characteristics of the three structures, we propose three sets of high-level, general requirements for DPsOC as follows.

First, sharing of digital content in multiple formats and multiple devices needs to be supported. The platform should support the diffusion of codified information (information that can be compressed into codes, such as financial information) and abstract information (information that can be assigned to a general phenomenon, such as ideal type) among members from different communities (Boisot and Child, 1999). Reciprocity is not required in this form of sharingcentered interactions, and impersonal relationships prevail among anonymous users. External control must be in place, and coordination is horizontal and self-regulating. Each actor is free to participate by pursuing her own goals.

Second, collaboration among community members that share some common interests, values, and trust needs to be supported. A limited reciprocity among anonymous users that contribute to the community 'discourse' must be favored. The admittance is based on self-selection, the participation is free, and there is a low level of monitoring. Coordination is still horizontal and self-regulating even though hierarchical and formal aspects must be present together with some form of negotiation.

Third, collective action requires a high level of scope congruence and an environment in which values, beliefs, and trust are shared. Membership is allowed upon selection and is followed by a socialization process in which personal relationships among small groups of identified users are reinforced through the exchange of uncodified and concrete information. Coordination is horizontal and carried out through mutual adjustments (reciprocity), while hierarchical and formal control can also be present. To be successful, the platform should provide mechanisms for negotiating goals and loyalty among members.

It is important to note that a single digital platform does not necessarily have to support all three social interaction 
Table 1 Comparison of information sharing, collaboration, and collective action

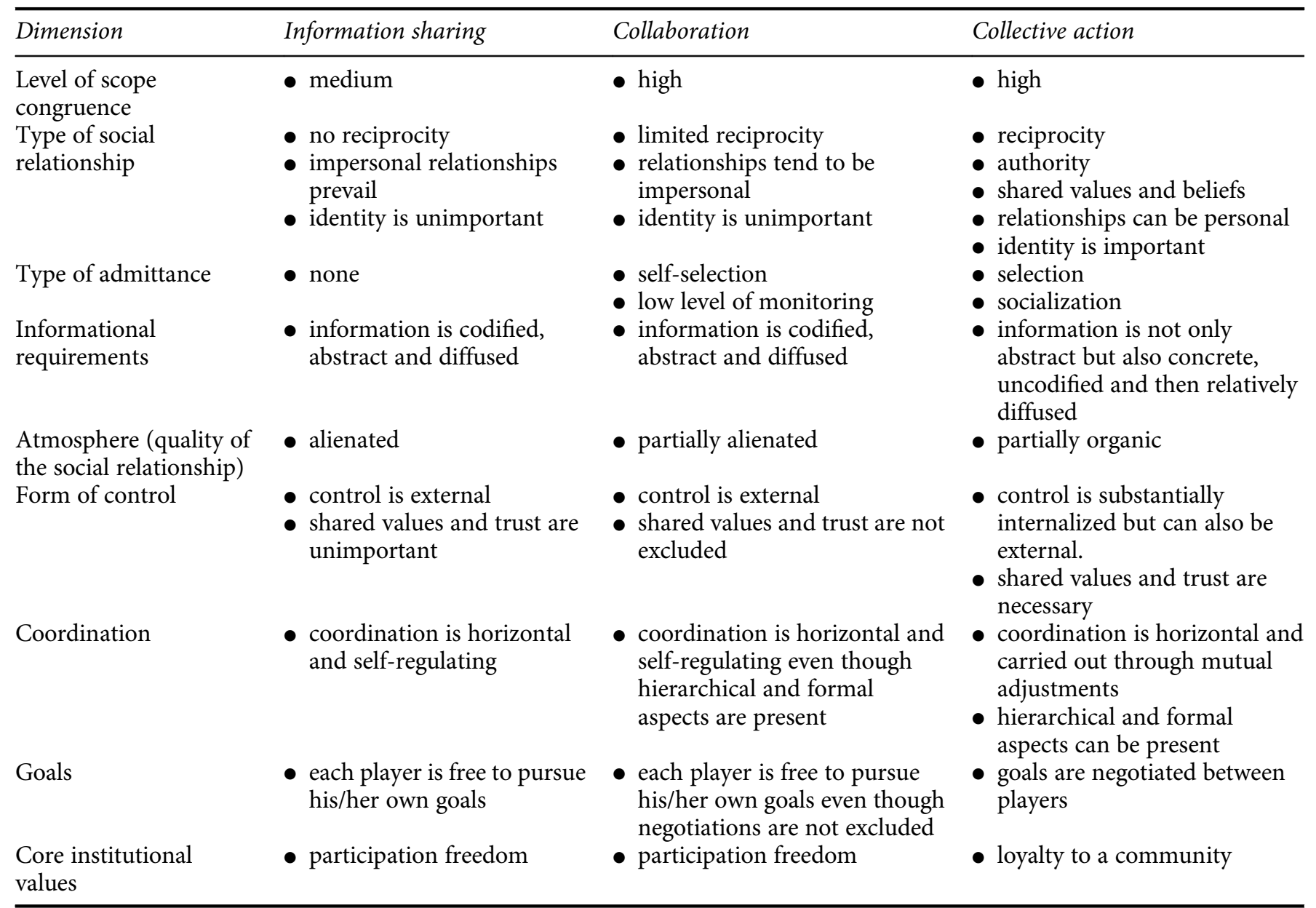

structures to their full extent because online communities vary in terms of their relative focus. For example, Twitter focuses mainly on information sharing, whereas Wiki communities focus mainly on collaboration.

\section{A design theory for digital platforms supporting online communities} (DPsOC)

Digital platforms support heterogeneous needs of users who act as both goal seeking individuals and online community members. As such, they need to be designed as architectures that provide the users with multiple IT capabilities and applications (Spagnoletti and Resca, 2012). Such architectures must be connected with existing infrastructures (e.g., social networking services) that provide the potential to reach a large number of new users for sharing digital content, collaborating on co-creation of physical or information goods, and enabling collective action within groups that share values and beliefs. Rather than having a fixed monolithic form, the overall platform architecture must be made of a set of elements that can be reconfigured to meet multiple community needs. Furthermore, the main functionalities must be tailored to multiple contexts reflecting the specific needs of different classes of users. Finally, the architecture must be flexible enough to embed new functionalities and to extend the initial scope toward unplanned emerging forms.
We translate the capabilities and conditions of three social interaction structures of online communities described in the previous section into a set of architectural requirements for three building blocks, including core components, interfaces, and complements (Table 2). Albeit not exhaustive, this schema provides an analytical framework for identifying, selecting, and prioritizing the elementary components of a digital platform and for guiding the design process of contextspecific platforms.

The first architectural requirement emerging from our analysis is related to the distinction between a common layer of core application services shared among the three social interaction structures and specific services (complements) supporting the different modes of interaction. The former provides a set of services based on the inner platform architecture or its living IT infrastructure (vom Brocke et al., 2014). The platform owner holds these services and controls their evolution with the purpose of exploiting the value of community interactions (Resca et al., 2013) and protecting information security (Baskerville et al., 2014). Complements are a collection of elementary IT capabilities made available by external players to satisfy the broad needs of online communities. Information sharing, collaboration, and collective action are combined in different ways by accommodating the requirements posed by the environment of the platform system. Therefore, in some cases, a digital platform 
Table 2 Architectural requirements of a digital platform supporting online communities

Online communities: social interaction structures

\begin{tabular}{|c|c|c|c|c|}
\hline & & Information sharing & Collaboration & Collective action \\
\hline \multirow[t]{3}{*}{$\begin{array}{l}\text { Platform } \\
\text { components }\end{array}$} & Core & \multicolumn{3}{|c|}{$\begin{array}{l}\text { IT application services: identity management, content and knowledge management, geo } \\
\text { information, workflow management, communication, authentication and authorization, social } \\
\text { network, analytics, and so on. }\end{array}$} \\
\hline & Interfaces & $\begin{array}{l}\text { Social network APIs, } \\
\text { Operating system APIs, } \\
\text { Open Data, multimedia } \\
\text { standards }\end{array}$ & $\begin{array}{l}\text { Social network APIs, Data } \\
\text { model, Ontology, Open Data, } \\
\text { Secure Protocols }\end{array}$ & $\begin{array}{l}\text { Social network APIs, Operating system } \\
\text { APIs, Secure Protocols }\end{array}$ \\
\hline & Complements & $\begin{array}{l}\text { IT capabilities for } \\
\text { consuming and generating } \\
\text { codified and abstract } \\
\text { information }\end{array}$ & $\begin{array}{l}\text { IT capabilities for coordinating } \\
\text { and negotiating codified } \\
\text { content among community } \\
\text { members }\end{array}$ & $\begin{array}{l}\text { IT capabilities supporting the exchange } \\
\text { of concrete and uncodified } \\
\text { information among trusted } \\
\text { community members }\end{array}$ \\
\hline
\end{tabular}

does not necessarily have all three interaction structures but may have only one or two structures. The link between core services and complements is guaranteed by a set of standards, protocols, and applications acting as interfaces. Taken together, we propose the following proposition that illustrates the general architectural arrangements through which DPsOC operate.

Proposition 1: To be effective, digital platforms that support online communities should combine core services and interfaces that enable complements in order to support a mix of information sharing, collaboration, and/or collective action.

When implementing modules for information sharing, ubiquitous access and device interoperability are key requirements. Since the virtual space is not tied to geography, community members should be able to access the platform anywhere, anyhow, and anytime, according with the specific services provided. The idea is to design a space in which users find elements easily so that they can participate actively. The architecture should support the filtering, aggregation, and viral diffusion of digital contents and should link to a large number of users through multiple devices. Furthermore, since weak ties prevail in content-sharing networks, the platform must be connected to popular online social networking services, such as Facebook or Twitter, in order to facilitate the dynamic evolution of community members and the circulation of news and updates. This leads us to formulate the second proposition:

Proposition 2: To be effective, digital platforms that support information sharing-centered online communities should be connected to popular online social networking services in order to enable the diffusion of codified and abstract information.

Online collaboration relies on the capability to manage a shared repository of codified and abstract information. Community members must be able to easily access relevant information, provide feedback through rating and comments and eventually generate new content by adding, recombining, modifying, and integrating contents contributed by other members. Such collaborative effort can occur among people who do not know each other, as long as their interests are temporarily convergent (Faraj et al., 2011). Platforms that support these processes must implement content management functionalities and rewarding mechanisms for engaging a large number of peers in generation and validation of new content. Both explicit and tacit rules are required to govern content co-creation. These rules can be strict and should be embedded in software modules because rule enforcement by human actors is difficult for heterogeneous members. For instance, an authentication and authorization module should allow the users to act anonymously using their virtual identity but should also implement some form of control in case of policy violation. Furthermore, a workflow should support coordination among community members to implement quality control mechanisms on new content. The third proposition of our design theory addresses this mechanism.

Proposition 3: To be effective, digital platforms that support collaboration-centered online communities should engage anonymous members of large and loosely coupled communities and embed in software modules peer control and coordination mechanisms in order to ensure the quality of new content.

Finally, IT capabilities for collective action provide a private, safe, and secure environment in which members have the opportunity to exchange information, reach a consensus, make a collective action, and act as a group to achieve a common goal. In such environments, the exchange of concrete and uncodified information (e.g., help request via instant messaging) enables intimate interactions and the exchange of resources both in the virtual and in the physical world. As trust is an important condition here, collective action functionalities support the creation of private groups of invited users whose identity is made explicit through reliable authentication methods. Advanced functionalities for managing access to shared resources together with both synchronous and asynchronous communication means must be provided in order to support the formation and the continuous evolution of close-knit social circles. The fourth proposition focuses on this mechanism.

Proposition 4: To be effective, digital platforms that support collective action-centered online communities should 
engage trusted members of small and tightly coupled communities in the exchange of concrete and uncodified information and provide coordination mechanisms.

\section{Research method}

The four propositions developed in the previous section offer an abstract conceptual representation of a design theory for DPsOC. The development of our design theory uses a twophase approach by which these initial propositions are validated, new propositions are derived, and nuanced insights are generated through two-way interactions between metalevel theory and expository instantiations of multiple real-life cases (Eisenhardt and Graebner, 2007; Yin, 2009). The overview of our research process is depicted in Figure 2.

In the first phase, we validate the four initial propositions using an in-depth analysis of the HOPES ${ }^{1}$ case, an European digital platform for elderly care assistance. HOPES stands for Help and social interaction for elderly On a multimedia Platform with E-Social best practices. The HOPES project started in September 2010 as a 3-year project, funded by the Ambient Assisted Living (AAL) European Union (EU) Joint Program. The project aims at developing an intelligent multimedia platform for enhancing the sociability and quality of life of elderly people by leveraging Web 2.0 technologies. The project goal is to design and build the prototype of a digital platform that supports multiple forms of interactions among members of the elderly social entourage.

Two of the authors have been directly involved in building and evaluating the HOPES platform by contributing to the project's requirement analysis, design, and evaluation phases. Therefore, we have access to a large amount of project material, in forms of deliverables, working documents, presentations, email messages, meeting notes, audio and video recording of focus group activities, etc. We use these data as the empirical settings for instantiating the four propositions and gaining additional insights that are contextualized in a specific digital platform. The platform supports all three social interaction structures. Therefore, the case allows us to validate all four propositions. We exploit the communicative and representational power of the IT artifact developed in the case for explaining how the above mentioned justificatory knowledge makes purpose and scope fit with principles of form and function. We analyze the case data through an iterative, interactive qualitative method. Two of us independently

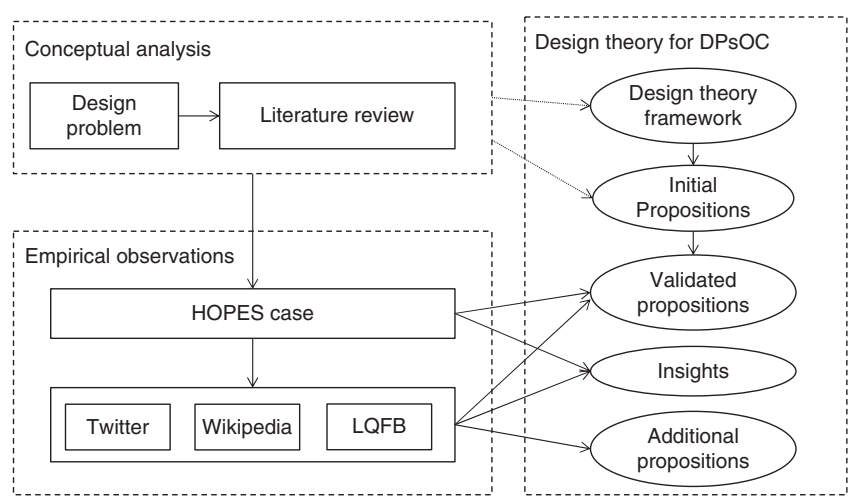

Figure 2 The research process. analyze the case data and code important themes and facts. Then, we discuss our results and resolve differences until no new insight can be found.

In the second phase, to strengthen the external validity of our findings, we analyze three additional cases of highly successful and popular digital platforms that support online communities, including Twitter, Wikipedia, and Liquidfeedback. We chose these cases because each of them emphasizes one of the three social interaction structures. We analyzed Twitter mainly for information sharing-centered online communities, Wikipedia for collaboration-centered ones, and Liquidfeedback for collective action-centered ones. The data sources include prior literature, websites, and various online documents. We use the same iterative, interactive qualitative method to analyze these data in order to validate our design theory and generate new propositions and insights. After going through these two phases of empirical validation, our design theory for DPsOC has been modified and refined, and has benefited from additional contextualized insights.

\section{The case of a european digital platform for elderly care assistance}

The European digital platform for elderly care assistance represents a valuable context for studying the design of a DPsOC. The platform instantiates the architecture of a digital platform aimed at supporting all three social interaction structures, and hence, it provides an expository instantiation of the phenomenon under investigation. Moreover, the project has involved eight partners from four EU countries, including two universities, a leading IT company, a small enterprise, and five end-user organizations. Such variety of cultures, fields of expertise, and specializations provide a unique opportunity to design a digital platform from multiple perspectives.

\section{Purpose and scope}

The European project addresses the elderly sociability problem by integrating a range of IT-based services. All these services are intended to be provided through a Web 2.0 approach by supporting social interactions and the production of user generated content called 'e-Social Best Practices' (eSBP). Users are seen as both recipients and sources of different types of information that are both generated and circulated in service of satisfying their needs and improve the quality of life for the elderly. Such users do not act in isolation but their actions are embedded in their offline and online social and institutional settings.

The structures and components of the social interactions surrounding the elderly represent a crucial part of the platform environment. In the early phases of the project, an analysis was conducted on the composition of the social support networks of elderly people in order to understand their communicative behavior, the channels supporting social relations, and the social rules that govern interactions. The differences between the forms of communication with loved ones, with friends and peers, and with institutions and civil society require different interaction environments, which were conceptualized as distinct virtual spaces. Such virtual spaces were named after three metaphors of interaction as described below: the Public Square, the Social Window, and the Courtyard. 
The Public Square refers to the metaphor of a place where members of local communities can physically meet to share knowledge and participate in social life. Within this sharing environment, actors make available their own contents on the Internet, creating a resource available to all. Free participation and spontaneous action of the participant are allowed, and the aggregation of individuals who perform similar tasks independently is supported. The requirements for the Public Square include: the ability to enter and exit the area without public notifications, the protection of privacy, and the compliance with standards of shared behavior (e.g., codes of conduct).

The Social Window supports a less invasive communication through the exchange of multimedia messages as a way to indicate emotional closeness without causing the concern of invading the privacy of others. Within this virtual place, actors collaborate for sharing knowledge (i.e., eSBP) and for creating content in a collaborative way. This requires rules and coordination. Participants are required to adapt their behavior to be in tune with others, and this is achieved by making conversation a continuous process. Thus, the focus of the Social Window metaphor is on collaboration, in which a greater alignment is needed between group objectives and individual objectives. This is the typical behavior of the peer production and open source communities. The personal appropriation of results obtained is not possible, and collective decisions through negotiation mechanisms must be supported.

Finally, the Courtyard refers to the metaphor of a place where more intimate and empathic social relationships are supported in order to enable the collective action of individuals who provide assistance to an elderly. Common rules are established by small groups of actors who are selected through an invitation process. In this environment, regulations are complex and situated in the context of the elderly. A close coordination is required, and decisions made by the group prevail over personal interests. Within these tightly coupled and small communities of actors, a strong internal cohesion is expected, and the participant identifies herself with this social unit. The main requirements are task coordination, event scheduling, and the capability to communicate through simple gestures in a personal and intimate way with the elderly and other community members.

These three metaphors of social spaces give an idea of the atmosphere that characterizes the three interaction environments of the digital platform. The Public Square refers to an environment in which information is exchanged without any form of control or limitation. The Social Window represents a scenario in which the users can observe the environment but can also contribute to the discourse. Finally, the Courtyard indicates an area of the platform in which a group of users can share values and pursue a common goal through collective action.

\section{Principles of form and function}

The three types of social interaction environments described above give rise to the requirements specifications for a set of IT capabilities that can be combined in multiple ways to support the emergence of community behaviors in different contexts. Using the lenses of our theoretical framework, we represent the architectural requirements for the platform in Table A1 in Appendix A. A set of services, including authentication and authorization service and semantic service, has been identified as core components of the platform. The architecture benefits from the flexibility to generate complements on top of external systems. These systems include the Facebook social graph, the Android mobile operating system, the MediaWiki open source software, and infrastructural and application services available through Azure, the Microsoft's cloud platform.

The purpose and scope of the Public Square materialize through the implementation of a mobile application that enables information sharing among elderly individuals and organizations. The main objective is to foster the exchange of information about local social events for increasing the participation of the elderly. The events are automatically collected from public Facebook pages of the voluntary associations, charities, parishes, and so on, and filtered according to the elderly needs. Another tool that supports the Public Square is the Online Magazine (OM). It provides both the elderly and her social entourage with personalized, certified content in the form of e-Social Best Practices (eSBP) that is dynamically updated by certified content providers. Figure A1 in Appendix A shows how different tools support three virtual spaces.

The Social Window is implemented through a web-based system enabling the collaboration among formal and informal caregivers. The functionalities of $\mathrm{OM}$ and the Rally Round topic Centered (RRtC) collectively enable users to comment in their own language and circulate eSBP through the platform. $\mathrm{RRtC}$ is one of the two components of the Rally Round sites in which a set of coordination functionalities are implemented to support social interaction of large user groups whose members share interest on a specific topic. eSBP rating functionality and automatic translation service allow the formation of largescale collaborative communities with multiple cultures and languages.

The Courtyard is implemented through a restricted webbased system that enables the collective action of small groups of individuals to provide assistance to a specific elderly. The Rally Round elderly Centered ( $\mathrm{ReC})$ is the second component of Rally Round sites. It provides the environment in which users can experience intimate and empathic relationships and coordinate themselves to enhance the social interactions and the quality of life of the cared person. Once a user sets up an $\mathrm{RReC}$, she invites additional members to join this private group and eventually, the elderly to be assisted. A shared calendar, a private wall, a video chat, and a list of contacts of key members of the elderly's social support network are the main features of these private groups, by which members coordinate themselves for discussing relevant issues and providing better support to the elderly.

A modular architecture has been defined for mapping the functional elements presented above with the IT components and their interfaces. The resulting schema consists of three building blocks, as shown in Figure 3. The central building block consists of the main IT components (the web platform), which implement a portion of the collaboration (Social Window) and collective action (Courtyard) modules. The mobile application called GetOut! implements the information sharing module (Public Square), which can connect to the core platform through an interface. The external component, Facebook platform, is connected to the web platform through the interfaces, enabling the exchange of information with the web platform and the GetOut! mobile application. Therefore, the platform is seen as a set of core services and interfaces 


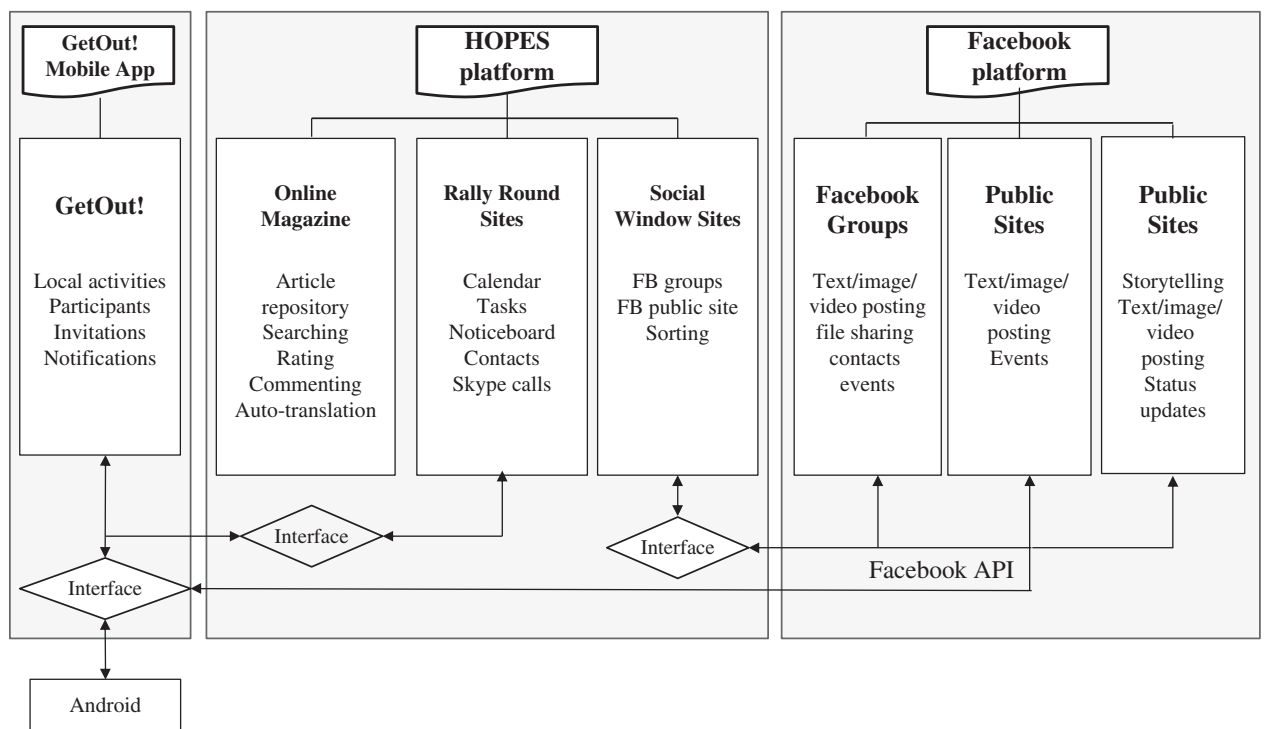

Figure 3 The HOPES platform architecture.

complemented by some external modules that provide additional IT capabilities for supporting information sharing, collaboration, and collective action.

\section{Insights from the case}

According to our design theory framework, testable propositions can be derived from the purpose and scope of DPsOC and their principles of form and function. Our analysis of the European digital platform case provides an empirical instantiation of the architectural requirements listed in Table 2. The purpose and scope of the platform are linked with its principles of form and function through the lenses of our conceptual model. In addition to validating the four initial propositions, the case also helps to discover additional insights that extend the extant literature on the architecture of a DPsOC. These insights are discussed below and summarized in Table 3. Furthermore, we discuss how evidences collected in the case inform our theoretical understanding of the problem domain.

\section{Digital platform architecture}

The case provides an example of a modular system that reflects the architectural requirements of a DPsOC. It provides an instantiation of a digital platform that combines core services and interfaces that enables complements to support information sharing, collaboration, and collective action. The environment of the platform is made of a large number and a variety of social networks with different characteristics in terms of needs, structure, and geographic distribution. Such highly complex and volatile environment challenges the task of system decomposition and the identification of modules that ensures platform flexibility without losing the benefits of system integration (Brusoni et al., 2007). The three metaphors of social interaction represent the projection of the general social interaction structures in the specific domain of the platform.

A second aspect to be reflected upon is related to the concept of the layered modular architecture (Yoo et al.; 2010). The earlier description of the platform components highlights the multi-layered nature of the platform, which spans from devices (e.g., smartphone, tablet, personal computer, and so on) to application functionalities (e.g., $\mathrm{OM}$, wiki, RReC, RRtC, and so on) and contents (e.g., e-SBP, post, and so on). Self-reinforcing mechanisms (Henfridsson and Bygstad, 2013) must be enacted in order to ensure the evolution of the platform technology affordances (Faraj et al., 2011). The case shows how these mechanisms can be deployed at each level of DPsOC architecture. The development of new content (e.g., e-SBP), the adoption of new functionalities within private groups (e.g., $\mathrm{RReC}$ ) and the scaling in external reach through mobile interfaces (e.g., Android) provide examples of self-reinforcing mechanisms in the content, service, and device layers respectively, ensuring platform evolution.

The generativity of digital products has also emerged as an important driver in the case, when software development teams from different institutions and countries have engaged in the design and production of peripheral modules (e.g., GetOut!, Facebook interface, HOPES Semantic Platform). Interfaces were a key element for ensuring platform evolution and enabling heterogeneous actors to implement new capabilities (Yoo et al., 2010). Interfaces can be thought of as the surface of the platform, and their degree of generativity determines much of the adaptability of a platform to its environment (Tiwana et al., 2010; Yoo, 2013; Zittrain, 2006, 2013). These architectural features trigger innovation, enable new organizational and strategic relationships (Yoo et al., 2012), and provide the opportunities to exploit the potential of digital ecodynamics (El Sawy et al., 2010). However, they could also generate tensions between platform owners and external developers (Tiwana et al., 2010). Such tensions have emerged many times during the European project whenever a new idea coming from the researchers and end-user organizations challenged the project plan and introduced new interdependencies with existing platforms and infrastructures.

Another insight is related to the management of shared data resources which challenge conventional norms of ownership, roles, and rules (Yoo et al., 2012). A common characteristic of 
Table 3 Summary of insights from the HOPES case

\begin{tabular}{ll}
\hline Main construct & Proposition \\
\hline $\begin{array}{l}\text { Digital platform } \\
\text { architecture }\end{array}$ & $\begin{array}{l}\text { To be effective, digital platforms that support } \\
\text { online communities should combine core } \\
\text { services and interfaces that enable complements } \\
\text { in order to support a mix of information } \\
\text { sharing, collaboration, and/or collective action. }\end{array}$
\end{tabular}

Mechanisms for information sharing collaboration

Mechanisms for collective-action
To be effective, digital platforms that support information sharing-centered online communities should be connected to popular online social networking services in order to enable the diffusion of codified and abstract information.

To be effective, digital platforms that support collaboration-centered online communities should engage anonymous members of large and loosely coupled communities and embed in software modules peer control and coordination mechanisms in order to ensure the quality of new content.

To be effective, digital platforms that support collective action-centered online communities should engage trusted members of small and tightly coupled communities to exchange concrete and uncodified information and to provide coordination mechanisms.
Additional insights

- Decomposition and module identification

- Incompleteness and unknowable boundaries

- Innovation, adoption and scaling as mechanisms of platform evolution

- Standardized interfaces for generativity and adaptation

- Intertwinement between platform architecture and governance

- Ethical reasoning in platform architecture design

- Decentralized filtering for fluidity

- Infrastructure interfaces for boundary shaping

- Flexible coordination for combinatorial innovation

- Semantic functionalities for knowledge base evolution

- Synchronous and asynchronous communication for convergence and conveyance

- Groupwork capabilities for constrained serendipidy digital platforms is their capability to collect digital traces on user behavior as by-products of pervasive digital technologies. In the case, this represented an important issue in the design process. Digital traces are particularly important because they are related to the health conditions of the elderly. They could be of potential interest to many players such as pharmaceutical and insurance companies. These data often represents the main asset for platform owners who implement pricing strategies for services. Therefore, preserving privacy and security through adequate architectural choices must be a key requirement. The case suggests the new forms of risks and the unintended consequences that may arise in the design of a DPsOC. The case suggests that ethical reasoning is an integral part of the design of platform architecture, security and privacy mechanisms, and analytics capabilities in order to balance the public interest with business value (Myers and Venable, 2014; Pang et al., 2014).

\section{Mechanisms for information sharing}

The information-sharing module needs to facilitate free and spontaneous participation from the users. As sharing of codified information in online communities often involves impersonal, alienated, non-reciprocal social relationships and weak ties, we found it important for the information-sharing module to be linked to popular social networking services.
Otherwise, feedback and feed-forward loops of information exchanges are not likely to emerge. In the case we studied, information sharing is achieved by enabling users to access information gathered from Facebook public sites through a mobile application (i.e., GetOut!) and to circulate this information within social support networks. Mechanisms for information sharing connect multiple data sources to the platform's core services (e.g., semantic search) that allow information to flow toward a large number of recipients. Unlike broadcast models of communication, filtering is decentralized and information reaches users via multiple paths. The GetOut! application mobilizes new intermediaries (e.g., social support network members) by providing them with capabilities to filter and circulate information. The decentralization of filtering capabilities increases the fluidity of information exchanges among community members (Faraj et al., 2011).

From the platform owner's standpoint, the architecture of a DPsOC plays an important coordinative role in managing the relationship with communities of users. The convergence of digital technologies and the pervasive diffusion of smart devices create the conditions for continuously reshaping the boundaries of online communities. The case offers insights on the mechanisms for orchestrating flows of information. By selecting the information sources (e.g., public health, voluntary associations) and the devices used for running complementary modules (e.g., Android smartphone), the 
boundaries of online communities are reshaped and new users can be engaged in mass-coordination processes. Therefore, a key enabler for the effective diffusion of codified and abstract information within online communities is the availability of interfaces with existing infrastructures that allow the platform connection to external data sources and smart devices.

\section{Mechanisms for collaboration}

The collaboration module needs to enable community members to share common interests and engage in collaborative actions through horizontal coordination and self-regulation. To this end, users should be able to browse and search items that reflect different domains of interest and to add value to them. These items may include articles, videos, or other forms of digital content, such as e-SBP and topic-centered groups. The case showcases how the editable, interactive, open and distributed nature of digital artifacts (Kallinikos et al., 2013) enables forms of co-creation and combinatorial innovation. The platform allows community members to build on other members' contributions by integrating heterogeneous multiple knowledge sources through adaptive emergent coordination mechanisms (Yoo et al., 2012), such as blogs and discussion forums.

The collaboration capabilities of the European digital platform we studied have been implemented through the mash-up of different modules providing services for accessing, rating, commenting, and translating existing knowledge as well as services for coordinating the collaborative effort in generating new content. The certification of user-generated content has involved professional domain experts whose collaboration is supported by the functionalities of SemanticMediaWiki, ${ }^{2}$ a semantic enhanced extension of the platform also used by Wikipedia. These functionalities have proven to be essential for dealing with the continuous improvement of e-SBP and for managing the dynamic network of concepts introduced by users from different countries. Therefore, ontologies and semantic modules are the main building blocks for managing the evolution of the knowledge base and for the provision of personalized contents to community users to foster the participation that leads to content co-creation.

\section{Mechanisms for collective action}

In collective action, the exchange of concrete information plays an important role in enabling intimate interactions and resource mobilization in relatively small and tightly coupled communities of trusted members. Coordination is horizontal and carried out through mutual, reciprocal adjustments, although hierarchical and formal control can also be present. The collective action module needs to provide effective coordination mechanisms for negotiating goals and boosting loyalty among members. In the case we studied, private groups formed in Rally Round elderly Centered provide such environments by allowing the members to interact with one another and mobilize resources to pursue the common goal of supporting the elderly.

The case offers insights on two additional architectural requirements of collective action. The first is related to the capability to support both synchronous and asynchronous communication among community members in order to ensure convergence as well as conveyance (Dennis et al., 2008). The capability of synchronous interaction characterizes collective action modules in which deliberation processes for collective decision making must be supported. In the case, teleconference functionalities (i.e., Skype) have been integrated in Rally Round elderly Centered to facilitate the exchange of concrete information in a trusted and intimate environment.

The second architectural requirement is related to the capability to facilitate the emergence of ad hoc solutions to situated problems. The RReC presents the typical characteristics of a group work environment with its functionalities for inviting members, posting and commenting external links, managing a shared calendar, and assigning tasks. However, as $\mathrm{RReC}$ provides such group work capabilities for social circles made of professional employees and voluntary members, mechanisms for collective action support the establishment of temporary units addressing contingent needs, and hence enact what is referred to as 'constrained serendipity' (Yoo et al., 2012).

\section{Further empirical observations}

The insights from the earlier case introduce concepts such as fluidity of information, validity of content, and transparency of transactions as important requirements of a DPsOC. In this section, we analyze three additional cases to identify the mechanisms supporting those concepts, to strengthen the validity of our design theory, and to derive additional propositions.

\section{Twitter: a case for effective information sharing}

Twitter is a microblogging tool launched in October 2006 with over 270 million monthly active users in 2014. It lets you write only brief text messages, limited to 140 characters. A user would have a short profile, including personal information, the number of tweets posted, the list of people the user follows, and the list of people who follow the user. Users use Twitter for daily chatter (posts related to daily activities), conversations (one can tag another user by using the @ symbol, followed by the username), and sharing URLs that lead to information such as news (Java et al., 2007). Tweets can be posted and read on different devices and reposted on thirdparty applications. The retweet mechanism enables the spread of information beyond the reach of the original user's followers (Kwak et al., 2010).

Twitter enables software developers to build and sell applications that interact with the core platform services by means of APIs and open standards (e.g., OAuth for managing authorizations). By acting on its APIs, the platform owner regulates boundary conditions and hence influences community behaviors. Twitter core services mainly provide information-sharing capabilities by exploiting the generative effects of linking its social graph to external services and devices through open interfaces. Figure B1 in Appendix B shows the core components, complements, and interfaces of the Twitter architecture.

Twitter provides an expository instantiation of the IT capabilities needed for supporting information sharingcentered online communities. The shortened URLs represent an example of codified information exchanged among communities of users. The capability to define hashtags and to use them for filtering content provides an example of the exchange of abstract information. The social network to which Twitter is 
openly connected is potentially the network of all Internet users and, in many cases, of all mobile device owners via SMS, mobile clients, and location-based services. The latter provides an important means for improving the fluidity of a platform (Faraj et al., 2011) by circulating timely and contextualized information that are relevant for the users in a specific moment and geographical location. Therefore, in addition to validating Proposition 2, the analysis of the Twitter case leads us to draw an additional proposition.

Proposition 2.1: To be effective, digital platforms that support information sharing-centered online communities should ensure fluidity by enabling the timely exchange of contextualized information through mobile services.

\section{Wikipedia: a case for sustained collaboration online community}

Wikipedia is a collaboratively edited, free online encyclopedia with more than 30.3 million articles in 287 languages, including about 4.4 million in the English Wikipedia. ${ }^{3}$ Wikipedia is written collaboratively by volunteers around the world, and its community (a.k.a., Wikipedians) (Ayers et al., 2008) is composed of, as of 2014, approximately 43.6 million registered user accounts across all language editions.

Each Wikipedia article consists of the Article page and the Talk page as its core components. The Article page displays the main content of the article, and the Talk page helps to coordinate work among editors by providing forums and tools. The Article page and the Talk page each consists of page tabs such as Read, Edit, View Source, and View History. The Article page includes different language editions, recent changes, bibliography, category tags, mobile view, print/export options, and various links to related articles, and developer page. The Talk page includes discussion forums, article milestones, and links to reference desk, help desk and village pump. These core components are interfaced with various complements, including bots, JavaScript client programs, enduser applications, search engines, and sister projects, such as Wikimedia Commons, Wikiquote, Wikisource, and Wikibooks. MediaWiki, a custom-made, free and open-source wiki software platform, provides a rich core feature set and a mechanism to attach extensions to provide additional functionality. MediaWiki has an extensible web API that provides direct, high-level access to the data contained in the MediaWiki databases. Figure B2 in Appendix B shows the core components, complements, and interfaces of the Wikipedia architecture.

In principle, almost all of the Wikipedia articles can be edited by anyone. This open nature of Wikipedia has led to concerns about the accuracy of information, the amount of vandalism, and the quality of writing (Priedhorsky et al., 2007). To address this issue, a complex governance structure has been created and has evolved over time. For example, the Wikipedians have various roles, ranging from administrators to account creators, autopatrollers, bots, bureaucrats, checkusers, edit filter managers, file movers, importers, IP-block exempt, oversighters, and ombudsmen (Simonite, 2013). In addition, the articles receive different levels of protection, ranging from full protection to template protection, semi-protection, creation protection, move protection, upload protection, pending changes protection, permanent protection, and cascading protection. ${ }^{4}$ Through its pervasive accessibility and connections with existing social networking services, Wikipedia engages many different types of users to both view and generate content.

The MediaWiki API provides a means for developing services such as vandal-fighting tools that protect content, because protecting existing content is as important as ensuring the validity and quality of the content in the first place. Such mechanisms can be embedded in software algorithms and protocols in order to simplify coordination for continuously ensuring content validity. Therefore, in addition to validating Proposition 3, the analysis of the Wikipedia case leads us to draw an additional proposition.

Proposition 3.1: To be effective, digital platforms that support collaboration-centered online communities should embed a means to continuously ensure the validity of existing content.

\section{Liquidfeedback: a case for collective action}

LiquidFeedback (LQFB) is a digital tool designed to accommodate and promote opinion formation and decision making through online communities. It combines aspects of both representative and direct democracy (Päivärinta and Sæbø, 2006; Sæbø et al., 2011). It is not only possible to vote directly on a specific issue but also to delegate voting that can be revoked anytime (De Cindio and Stortone, 2013). LQFB has been successfully used by Pirate Parties across Europe and by the Five Stars Movements in Italy for the convention preparation and policy formulation. However, the platform use is not limited to political parties and social movements. It is a deliberative tool in which users submit initiatives related to any issue. All initiatives are subject to a vote, according to the Schulze (2011) method that surveys preferences and the approval of one or more initiatives. The identification and authentication policy followed by LQFB aims to select only concerned citizens so that a strongly committed community is formed. Participants must be invited by the platform administrator, and very detailed personal information is required to record a vote (De Cindio and Stortone, 2013).

The system supports core components such as collective decision processes, user identity management, and software development process. Users invited by the platform owner can build their own network of contacts, browse the history of their activities, and delegate (and withdraw delegations from) other users to vote for initiatives on their behalf. Each user can initiate a new collective decision process, express her interest, and make recorded votes. The LQFB API is a key element of the platform in that it connects the system to its external dependencies such as RocketWiki, and it allows the interoperability with external applications in which LQFB is integrated with or extends its functionalities. Figure B3 in Appendix B shows the core components, complements, and interfaces of the LQFB architecture.

The core functionalities of LQFB lend itself to be an ideal instantiation of an IT artifact that supports the exchange of concrete and uncodified information among trusted community members. It provides a means for inviting users and for allowing them to manage their profile, contacts, and voting delegation in a trusted environment. In addition, it provides a workflow for proposing issues and initiatives, checking their relevance within the community, discussing with interested 
members, and finally, voting in a recorded way. ${ }^{5}$ Since trust and shared values and beliefs are key requirements for supporting collective decision-making in online communities, it is crucial to ensure the transparency of the overall process.

The LQFB architecture offers important insights on how to achieve transparency in online settings. First, it is based on open source software solutions, which ensure the possible inspection of source code. Second, it is not offered as a service except for public testing, while its common use requires the integration of its core functionalities within external systems (i.e., openDCN ${ }^{6}$ ) owned by people and organizations that members can trust. This result is achieved through the collaborative work of a community of developers engaged in the maintenance and evolution of the core modules and their API specifications. Platform managers who are willing to foster collective action can benefit from the integration of LQFB in their portals and applications. Therefore, in addition to validating Proposition 4, the analysis of the LQFB case leads us to draw an additional proposition.

Proposition 4.1: To be effective, digital platforms that support collective action-centered online communities should ensure the transparency of collective decision-making process by integrating deliberation and voting functionalities in trusted environments.

\section{Discussion and conclusions}

This study builds a design theory for DPsOC. As online communities demonstrate much more complex, emergent socio technical interactions than traditional information systems, there is a need, albeit a challenging one, for building a design theory for IT artifacts that support them. This research attempts to address this problem. We develop a design theory framework (Figure 1) that defines meta-level theoretical elements for DPsOC and that shows the role of expository instantiation in developing testable propositions. Drawing upon the transaction cost theory and the perspective of social interaction structures coping with free-riding problems, we identify three distinct forms of online communities information sharing, collaboration, and collective action.

As the role of digital platforms becomes increasingly important, our efforts to build a design theory need to shift from IT applications to digital platforms. We use architecture as a useful tool to derive a design theory linking technical components and functional requirements. For each form of online community we distinguish core elements, interfaces, and complements of digital platform architecture. The proposed conceptualization sheds light on the role that digital platform architectures have in triggering and supporting online community interactions. Software-based self-reinforcing mechanisms contribute to the sustainability of online communities, and hence, design principles reflect the intertwinement between platform architecture and governance.

This research generates and validates seven propositions that help to design and implement core elements, interfaces, and complements of digital platforms that support effective, sustainable online communities for information sharing, collaboration, and collective action. While the three forms of online communities have much in common, they are different in many respects as shown in Table 1. Design theories for DPsOC need to be developed with such factors in mind.
As summarized in Table 3, this research also produces additional insights on design of DPsOC.

Among the seven propositions we posit, Proposition 1 is an overarching proposition that concerns a general schema of digital platform architecture for representing the IT capabilities supporting the three social interaction structures. It spells out the constituencies of a platform and the relationship between its building blocks and the online community behavior. Propositions 2, 3, and 4 address the key requirements for the digital platform mechanisms supporting online communities focusing on each of the three interaction structures. The insights obtained from our field study of the European case reveal additional characteristics of digital platforms in terms of desirable features (e.g., privacy, boundary control) and tensions between users, platform owners, and external developers that emerge from the design process.

Propositions 2.1, 3.1, and 4.1 complement Propositions 2, 3, and 4, respectively. While Proposition 2 focuses on the importance of the connectivity to external social networking services to facilitate extensive diffusion of information, Proposition 2.1 points out the importance of using mobile services to facilitate timely exchange of contextualized information, thus ensuring the fluidity of the online community. While Proposition 3 stresses the importance of ensuring the quality of new content co-created by multiple users, Proposition 3.1 addresses the need for continuously ensuring the validity of existing content. Lastly, while Proposition 4 argues for provision of coordination mechanisms facilitating the exchange of concrete and uncodified information, Proposition 4.1 stresses the importance of the transparency of decisionmaking process when acting collectively.

These seven propositions collectively can help the designer of DPsOC identify some of the key requirements and mechanisms needed to increase the likelihood of success in developing and sustaining online communities. Depending on the relative focus of a given online community among the three forms of social interaction, the designer may refer to relevant propositions for guidance. Since our propositions are high-level, conceptual principles, practitioners need to translate them into tangible, concrete requirements and capabilities that are situated in a specific context. This research is an important step toward the development of a valid, reliable design theory for digital platforms that support effective and sustainable online communities. When building a design theory for DPsOC, we believe that it would be more fruitful to take an architectural approach and look into common and unique roles of core components, interfaces, and complements, rather than viewing a digital platform as a monolithic entity. By doing so, we can build a design theory that is relevant not only to platform providers but also to a larger ecosystem, including partners, suppliers, and users.

One promising future research opportunity lies in advancing design theories for DPsOC by embracing the perspective of digital affordance (Zammuto et al., 2007). The design of the intersection of technology and organizational/social features can result in affordances such as visualizing work processes, real-time/flexible product and service innovation, virtual collaboration, mass collaboration, and simulation/synthetic reality. These affordances, in turn, can result in new ways of organizing online communities. We also call for future studies that further validate and test our propositions. Such studies would benefit from employing a variety of research methods, 
ranging from case studies to field surveys, online-data crawling, and agent-based simulation modeling. Lastly, future research could help to translate our propositions into more concrete design rules in specific empirical settings for a greater impact on practice.

\section{Acknowledgements}

The authors are grateful to Ola Henfridsson and three anonymous reviewers for their insightful comments and suggestions on earlier versions of this paper.

\section{Notes}

1 The website of this project is www.hopes-rand.com.

2 https://semantic-mediawiki.org/ (last accessed 29 August 2014).

$3 \mathrm{http}: / /$ meta.wikimedia.org/wiki/List_of_Wikipedias.

4 http://en.wikipedia.org/wiki/Wikipedia:Protection_Policy.

$5 \mathrm{http}: / /$ en.wikipedia.org/wiki/LiquidFeedback.

$6 \mathrm{http} / / / \mathrm{www}$. openden.org.

\section{References}

Ayers, P., Matthews, C. and Yates, B. (2008). How Wikipedia Works: And how you can be a part of it, San Francisco, CA: No Starch Press.

Balasubramanian, S. and Mahajan, V. (2001). The Economic Leverage of the Virtual Community, International Journal of Electronic Commerce 5(3): 103-138.

Baldwin, C. and Woodard, J. (2009). Platforms, Markets and Innovation, in A. Gawer (ed.) The Architecture of Platforms: A unified view, Cheltenham: Edward Elgar, pp. 19-44.

Baskerville, R. and Pries-Heje, J. (2010). Explanatory Design Theory, Business \& Information Systems Engineering 2(5): 271-282.

Baskerville, R., Spagnoletti, P. and Kim, J. (2014). Incident-Centered Information Security: Managing a strategic balance between prevention and response, Information \& Management 51(1): 138-151.

Benkler, Y. (2002). Coase's Penguin, or, Linux and The Nature of the Firm, Yale Law Journal 112(3): 369-446.

Benkler, Y. (2006). The Wealth of Networks: How social production transforms markets and freedom, New Haven and London: Yale University Press.

Boisot, M. (1995). Information Space: A framework for learning in organizations, institutions and culture, London: Routledge.

Boisot, M. and Child, J. (1999). Organizations as Adaptive Systems in Complex Environments: The case of China, Organization Science 10(3): 237-252.

Brusoni, S., Marengo, L., Prencipe, A. and Valente, M. (2007). The Value and Costs of Modularity: A problem-solving perspective, European Management Review 4(2): 121-132.

Butler, B.S., Bateman, P.J. and Gray, P.H. (2015). An Attraction-SelectionAttrition Theory of Online Community Size and Resilience, MIS Quaterly $\mathrm{X}(\mathrm{X}): 1-30$.

Ciborra, C. (1996). Teams, Markets and Systems: Business innovation and information technology, Cambridge: Cambridge University Press.

Coase, R.H. (1937). The Nature of the Firm, Economica 4(16): 386-405.

De Cindio, F. and Stortone, S. (2013). Experimenting LiquidFeedback for Online Deliberation in Civic Contexts, in M.A. Wimmer, E. Tambouris and A. Macintosh (eds.) Electronic Participation, Heidelberg: Springer, pp. $147-158$.

Demil, B. and Lecocq, X. (2006). Neither Market Nor Hierarchy Nor Network: The emergence of bazaar governance, Organization Studies 27(10): 1447-1466.

Dennis, A., Fuller, R. and Valacich, J. (2008). Media, Tasks, and Communication Processes: A theory of media synchronicity, MIS Quarterly 32(3): 575-600.

Eisenhardt, K.M. and Graebner, M.E. (2007). Theory Building From Cases: Opportunities and challenges, Academy of Management Journal 50(1): 25-32.

El Sawy, O., Malhotra, A., Park, Y. and Pavlou, P. (2010). Seeking the Configurations of Digital Ecodynamics: It takes three to tango, Information Systems Research 21(4): 835-848.
Evans, D.S., Hagiu, A. and Schmalensee, R. (2006). Invisible Engines: How software platforms drive innovation and transform industries, Cambridge, MA: MIT Press.

Faraj, S., Jarvenpaa, S.L. and Majchrzak, A. (2011). Knowledge Collaboration in Online Communities, Organization Science 22(5): 1224-1239.

Fischer, C., Winter, R. and Wortmann, F. (2010). Design Theory, Business \& Information Systems Engineering 2(6): 387-390.

Gawer, A. (2009). Platforms, Markets and Innovation: an introduction, in A. Gawer (ed.) Platforms, Markets and Innovation, Cheltenham: Edward Elgar Publishing, pp. 1-18.

Gregor, S. (2006). The Nature of Theory in Information Systems, MIS Quarterly 30(3): 611-642.

Gregor, S. and Jones, D. (2007). The Anatomy of a Design Theory, Journal of the Association for Information Systems 8(5): 312-335.

Hanseth, O. and Lyytinen, K. (2010). Design Theory for Dynamic Complexity in Information Infrastructures: The case of building internet, Journal of Information Technology 25(1): 1-19.

Henfridsson, O. and Bygstad, B. (2013). The Generative Mechanisms of Digital Infrastructure Evolution, MIS Quarterly 37(3): 907-931.

Hevner, A.R., March, S.T., Park, J. and Ram, S. (2004). Design Science in Information Systems Research, MIS Quarterly 28(1): 75-105.

Huysman, M. and Wulf, V. (2005). IT to Support Knowledge Sharing in Communities, Towards a Social Capital Analysis, Journal of Information Technology 21(1): 40-51.

Java, A., Song, X., Finin, T. and Tseng, B. (2007). Why We Twitter: Understanding microblogging usage and communities. Proceedings of the 9th WebKDD and 1st SNA-KDD 2007 workshop on Web mining and social network analysis, San Jose, CA, 56-65.

Jones, Q. and Rafaeli, S. (2000). Time to Split, Virtually: 'Discourse architecture' and 'community building' create vibrant virtual publics, Electronic Markets 10(4): 214-223

Kallinikos, J. (2011). Bureaucracy Under Siege: On information, collaboration and networks, in H. Stewart, C. Harris and M. Harro (eds.) Managing Modernity: Beyond Bureaucracy? Oxford: Oxford University Press, pp. 130-153.

Kallinikos, J., Aaltonen, A. and Marton, A. (2013). The Ambivalent Ontology of Digital Artifacts, MIS Quarterly 37(2): 357-370.

Kwak, H., Lee, C., Park, H. and Moon, S. (2010). What is Twitter, a Social Network or a News Media? Categories and Subject Descriptors. Proceedings of the 19th international conference on World Wide Web, New York, NY, pp. 591-600.

Langlois, R. and Robertson, P. (1992). Networks and Innovation in a Modular System: Lessons from the microcomputer and stereo component industries, Research Policy 21(4): 297-313.

March, S.T. and Smith, G.F. (1995). Design and Natural Science Research on Information Technology, Decision Support Systems 15(4): 251-266.

Myers, M.D. and Venable, J.R. (2014). A Set of Ethical Principles for Design Science Research in Information Systems, Information \& Management 51(6): 801-809.

Obar, J.A., Zube, P. and Lampe, C. (2012). Advocacy 2.0: An analysis of how advocacy groups in the United States perceive and use social media as tools for facilitating civic engagement and collective action, Journal of Information Policy 2(1): 1-25.

Olson, M. (1971). The Logic of Collective Action: Public goods and the theory of groups. Cambridge, MA: Harvard University Press.

Ostrom, E. (1990). Governing the Commons: The evolution of institutions for collective action, Cambridge, UK: Cambridge University Press.

Ostrom, E. (2000). Collective Action and the Evolution of Social Norms, The Journal of Economic Perspectives 14(3): 137-158.

Ouchi, W.G. (1980). Markets, Bureaucracies, and Clans, Administrative Science Quarterly 25(1): 129-141.

Päivärinta, T. and Sæbø, Ø. (2006). Models of E-Democracy, Communications of the AIS 17(37): 818-840.

Pang, M.S., Lee, G. and DeLone, W. (2014). IT Resources, Organizational Capabilities, and Value Creation in Public Sector Organizations: A publicvalue management perspective, Journal of Information Technology 29(3): 187-205.

Pradhan, S. and Odugbemi, S. (2011). The Contours and possibilities of open development. World Bank. [WWW document] https:// openknowledge.worldbank.org/handle/10986/6110, accessed on 14 January 2015. 
Williamson, O.E. (1985). The Economic Institutions of Capitalism: Firms, markets, relational contracting, International Social Science Journal 54(171): 67-82.

, Ren, J., Lam, S., Panciera, K., Terveen, L. and Riedl, J. (2007) Creating, destroying, and restoring value in Wikipedia. Proceedings of the ACM GROUP 07, New York, NY.

Pries-Heje, J. and Baskerville, R. (2010). Management Design Theories, in J. Pries-Heje et al. (eds.) IS Design Science Research. IFIP AICT 318, pp. 263-281.

Resca, A. (2006). Knowledge: Climbing the learning ladder to a 'phenomenological'view, Journal of Information Technology 21(3): 203-210.

Resca, A., Za, S. and Spagnoletti, P. (2013). Digital Platforms as Sources for Organizational and Strategic Transformation: A case study of the Midblue project, Journal of Theoretical and Applied e-Commerce Research 8(2): 71-84.

Rothaermel, F.T. and Sugiyama, S. (2001). Virtual Internet Communities and Commercial Success: Individual and community-level theory grounded in the atypical case of TimeZone.com, Journal of Management 27(3): 297-312.

Sæbø, Ø., Flak, L.S. and Sein, M.K. (2011). Understanding the Dynamics in e-Participation Initiatives: Looking through the genre and stakeholder lenses, Government Information Quarterly 28(3): 416-425.

Schulze, M. (2011). A New Monotonic, Clone-Independent, Reversal Symmetric, and Condorcet-Consistent Single-Winner Election Method, Social Choice and Welfare 36(2): 267-303.

Shirky, C. (2008). Here Comes Everybody: The power of organizing without organizations, New York, NY: Penguin Press.

Simon, H. (1996). The Sciences of the Artificial, 3rd edn, Cambridge, MA MIT Press.

Simonite, T. (2013). The Decline of Wikipedia. MIT Technology Review. [WWW document] http://www.technologyreview.com/featuredstory/520446/ the-decline-of-wikipedia/, accessed on 14 January 2015

Sonnenberg, C. and vom Brocke, J. (2012). Reconsidering the Build-Evaluate Pattern in Design Science Research, in K. Peffers, M. Rothenberger and B. Kuechler (eds.) DESRIST 2012, LNCS 7286, Heidelberg: Springer, pp. 381-397.

Spagnoletti, P. and Resca, A. (2012). A Design Theory for IT supporting Online Communities. Proceedings of the 45th Hawaii International Conference on System Sciences, Maui, HI, 4082-4091.

Spagnoletti, P. and Tarantino, L. (2012). User Centered Systems Design: The bridging role of justificatory knowledge, in R. Baskerville, M. De Marco and P. Spagnoletti (eds.) Designing Organizational Systems, LNISO. Vol. 1, Heidelberg: Springer, pp. 105-122.

Stanoevska-Slabeva, K. and Schmid, B. (2001). A typology of online communities and community supporting platforms. Proceedings of the 34th Hawaii International Conference on System Sciences, Maui, HI.

Stockdale, R. and Borovicka, M. (2006). Developing an Online Business Community: A Travel Industry Case Study. Proceedings of the 39th Hawaii International Conference on System Sciences, Kauai, HI, 1-9.

Tapscott, D. and Williams, A.D. (2008). Wikinomics: How mass collaboration changes everything, New York, NY: Portfolio.

Tiwana, A., Konsynski, B. and Bush, A.A. (2010). Platform Evolution: Coevolution of platform architecture, governance, and environmental dynamics, Information Systems Research 21(4): 675-687.

Tonnies, F. (1955). Community and Association: (Gemeinschaft und gesellschaft), London: Routledge \& Kegan Paul.

Ulrich, K. (1995). The Role of Product Architecture in the Manufacturing Firm, Research Policy 24(3): 419-440.

Van Aken, J.E. (2004). Management Research Based on the Paradigm of the Design Sciences: The quest for field-tested and grounded technological rules, Journal of Management Studies 41(2): 219-246.

Vom Brocke, J., Braccini, A.M., Sonnenberg, C. and Spagnoletti, P. (2014). Living IT Infrastructures - An ontology-based approach to aligning IT infrastructure capacity and business needs, International Journal of Accounting Information Systems 15(3): 246-274.

Walls, J., Widmeyer, G. and El Sawy, O.A. (1992). Building an Information System Design Theory for Vigilant EIS, Information Systems Research 3(1): 36-59.

Wilkins, A.L. and Ouchi, W.G. (1983). Efficient Cultures: Exploring the relationship between culture and organizational performance, Administrative Science Quarterly 28(3): 468-481.

Williams, R. and Pollock, N. (2008). Software and Organisations - The biography of the enterprise-wide system or how SAP conquered the world, London: Routledge.

Williamson, O.E. (1975). Markets and Hierarchies, Analysis and Antitrust Implications: A study in the economics of internal organization, New York, NY: Free Press.
Yin, R.K. (2009). Case Study Research: Design and methods, London: Sage Publications.

Yoo, Y. (2013). The Tables Have Turned: How can the information systems field contribute to technology and innovation management research? Journal of the Association for Information Systems 14(5): 227-236.

Yoo, Y., Boland, R.J., Lyytinen, K. and Majchrzak, A. (2012). Organizing for Innovation in the Digitized World, Organization Science 23(5): 1398-1408.

Yoo, Y., Henfridsson, O. and Lyytinen, K. (2010). The New Organizing Logic of Digital Innovation: An agenda for information systems research, Information Systems Research 21(4): 724-735.

Zammuto, R.F., Griffith, T.L., Majchrzak, A., Dougherty, D.J. and Faraj, S. (2007). Information Technology and the Changing Fabric of Organization, Organization Science 18(5): 749-762.

Zittrain, J. (2006). The Generative Internet, Harvard Law Review 119(1974): 1975-2040.

Zittrain, J. (2013). The Future of the Internet and How to Stop It, New Haven, CT: Yale University Press.

\section{About the Authors}

Paolo Spagnoletti is Assistant Professor at LUISS University of Rome, where he coordinates the Research Centre on Information Systems (CeRSI). He received his Ph.D. at LUISS and has been visiting fellow at LSE, GSU, University of Agder and University of St. Gallen. His current research interests include digital platforms design and governance, socio-technical approaches to IS development, and learning/adaptation in military organizations. His works are published in journals including Information \& Management, Communications of AIS, International Journal of Accounting Information Systems, and Journal of Theoretical and Applied E-Commerce Research. $\mathrm{He}$ has edited three books and is Executive Editor of the Springer series LNISO.

Andrea Resca, after his Ph.D. at LUISS University of Rome in 2009 is continuing to do research in the same university at the Research Centre on Information Systems (CeRSI) as a Postdoctoral fellow. The study of organizational transformation enabled by information technology has been object of investigation in the latest years in fields such as judiciary systems, cultural heritage, healthcare, and e-commerce. The Journal of Information Technology and the European Journal of Information Systems published some of his works.

Gwanhoo Lee an Associate Professor in the Kogod School of Business at the American University. He is also Director for Center for IT and the Global Economy. He received the Ph.D. degree from the University of Minnesota. His current research interests include complexity and agility in information systems development, global teams, complex adaptive systems, digital innovation, e-government, enterprise architecture, information privacy, and cyber security. He has published his research in journals including MIS Quarterly, IEEE Transactions on Software Engineering, Journal of Management Information Systems, European Journal of Information Systems, Communications of the ACM, Journal of Information Technology, Government Information Quarterly, and Information \& Management. 


\section{Appendix A}

Requirements and components in the HOPES case

Table A1 shows how the architectural requirements and components of the European case instantiate those of DPsOC.
This architectural schema depicts the association between each metaphor and the building blocks. Figure A1 illustrates tools that have been developed to support the social interactions.

Table A1 The HOPES architectural requirements

Online communities: social interaction structures

\begin{tabular}{lll}
\hline $\begin{array}{l}\text { Public Square } \\
\text { (Information sharing) }\end{array}$ & $\begin{array}{l}\text { Social Window } \\
\text { (Collaboration) }\end{array}$ & $\begin{array}{l}\text { Courtyard } \\
\text { (Collective action) }\end{array}$ \\
\hline
\end{tabular}

\begin{tabular}{|c|c|c|c|c|}
\hline \multirow[t]{3}{*}{$\begin{array}{l}\text { Platform } \\
\text { components }\end{array}$} & Core & $\begin{array}{l}\text { Authentication and } \\
\text { authorization services, } \\
\text { translation services, } \\
\text { semantic services, analytics }\end{array}$ & & \\
\hline & Interfaces & $\begin{array}{l}\text { APIs for interacting with } \\
\text { existing social graphs, APIs } \\
\text { for interacting with mobile } \\
\text { services }\end{array}$ & $\begin{array}{l}\text { APIs for interacting with existing } \\
\text { social graphs, APIs for } \\
\text { interacting with mobile services, } \\
\text { open data formats }\end{array}$ & $\begin{array}{l}\text { APIs for interacting with existing } \\
\text { social graphs, APIs for interacting } \\
\text { with mobile services, APIs for } \\
\text { coordination services }\end{array}$ \\
\hline & Complements & $\begin{array}{l}\text { IT capabilities } \\
\text { implementing the Public } \\
\text { Square metaphor }\end{array}$ & $\begin{array}{l}\text { IT capabilities implementing the } \\
\text { Social Window metaphor }\end{array}$ & $\begin{array}{l}\text { IT capabilities implementing the } \\
\text { Courtyard metaphor }\end{array}$ \\
\hline
\end{tabular}

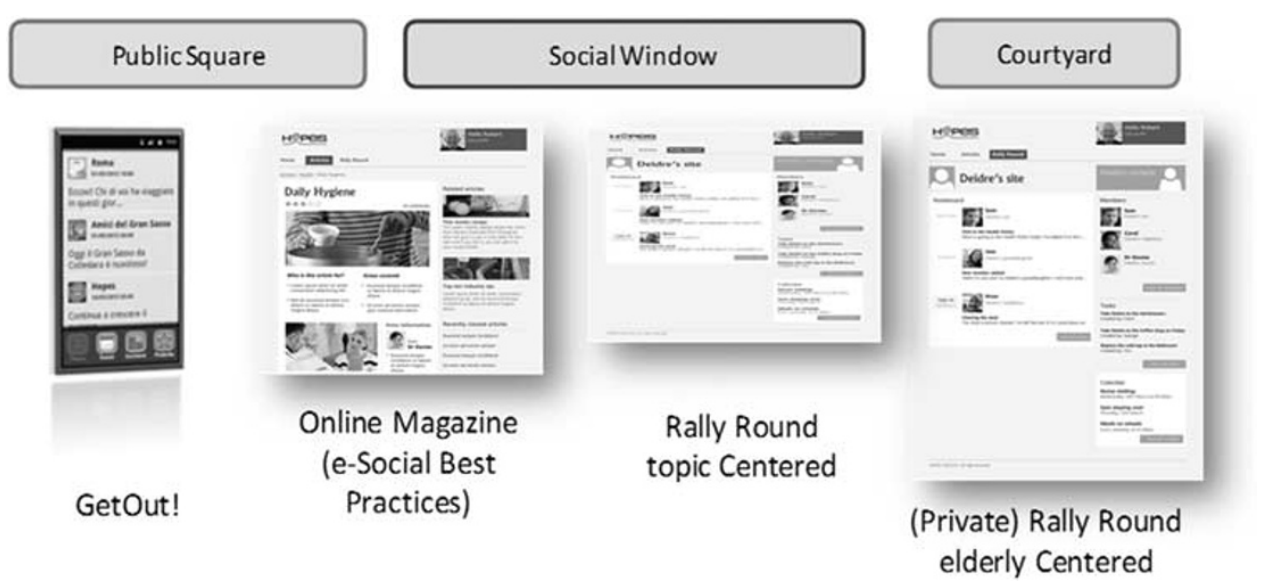

Figure A1 Supporting tools for HOPES.

\section{Appendix B}

The architectures of twitter, wikipedia, and liquidfeedback The functional architecture of Twitter, Wikipedia and LiquidFeedback is represented in Figures B1, B2 and B3 respectively.
The three schemas are drawn upon the analysis of the platforms through the lens of our theory. The main building block consists in core IT components that enable and sustain complements through a set of interfaces. 

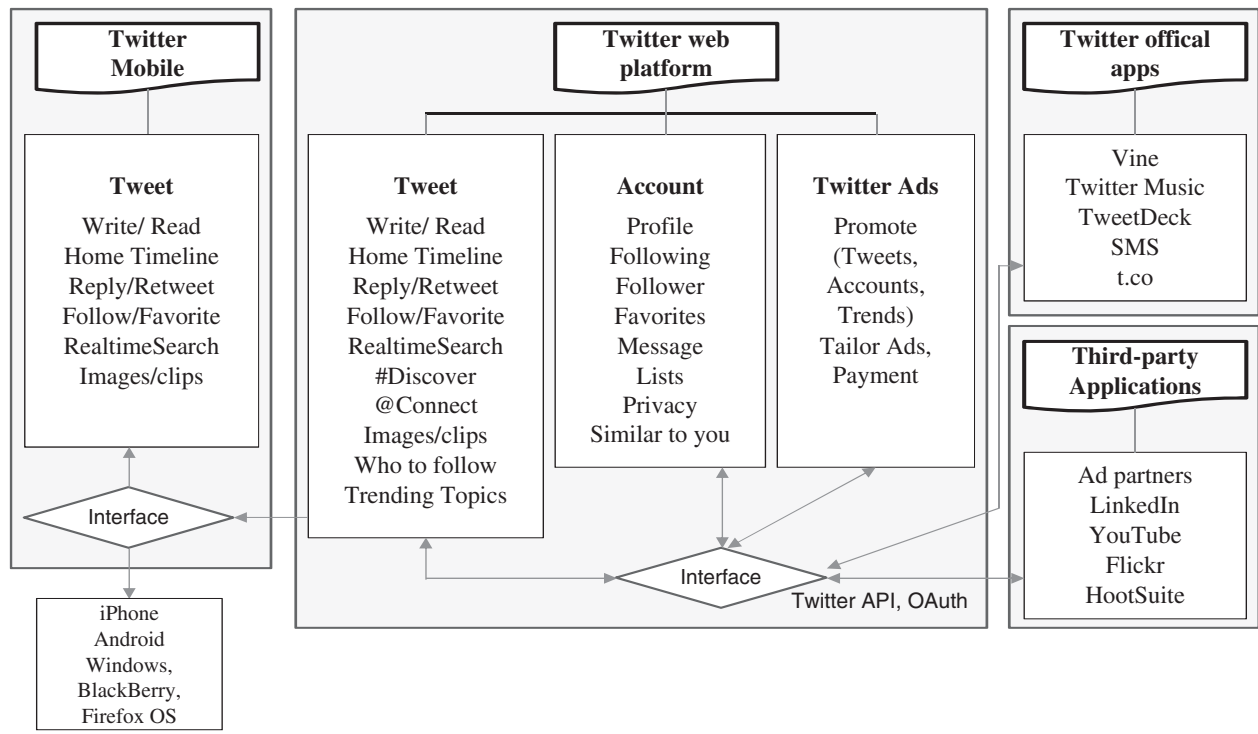

Figure B1 The twitter architecture.
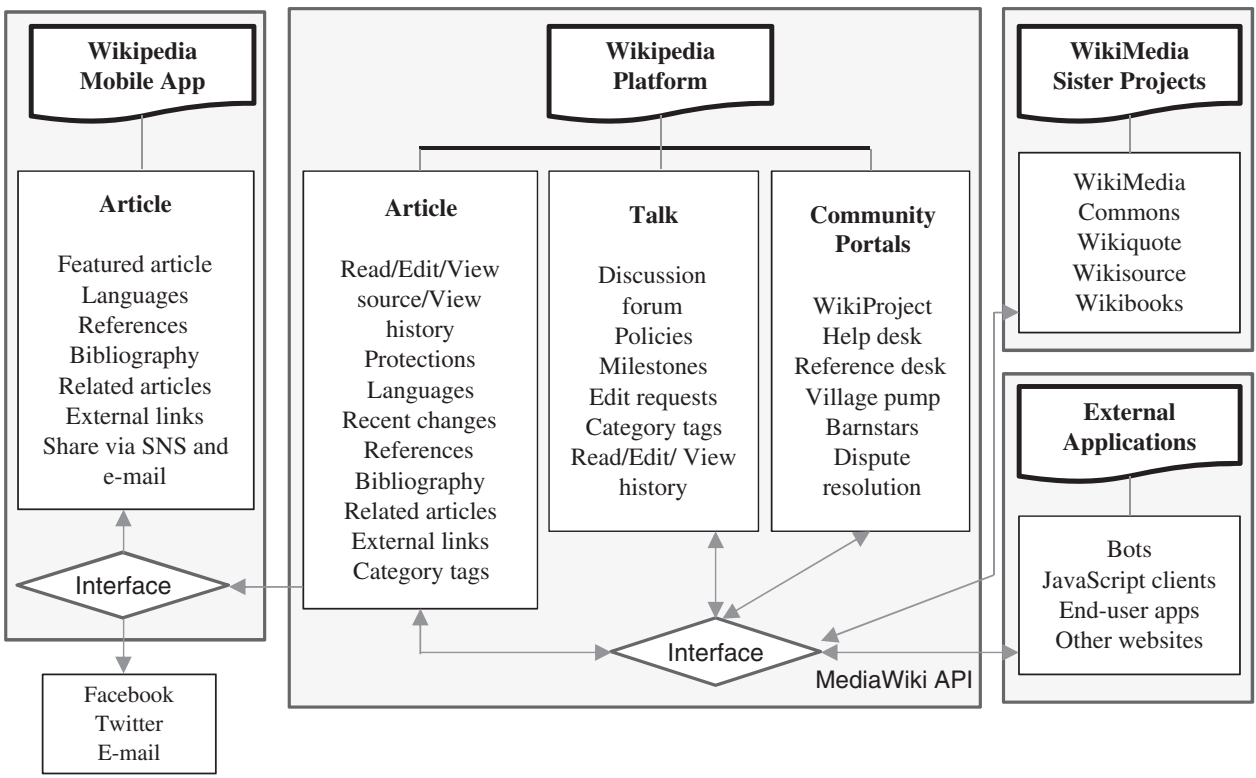

Figure B2 The wikipedia architecture.
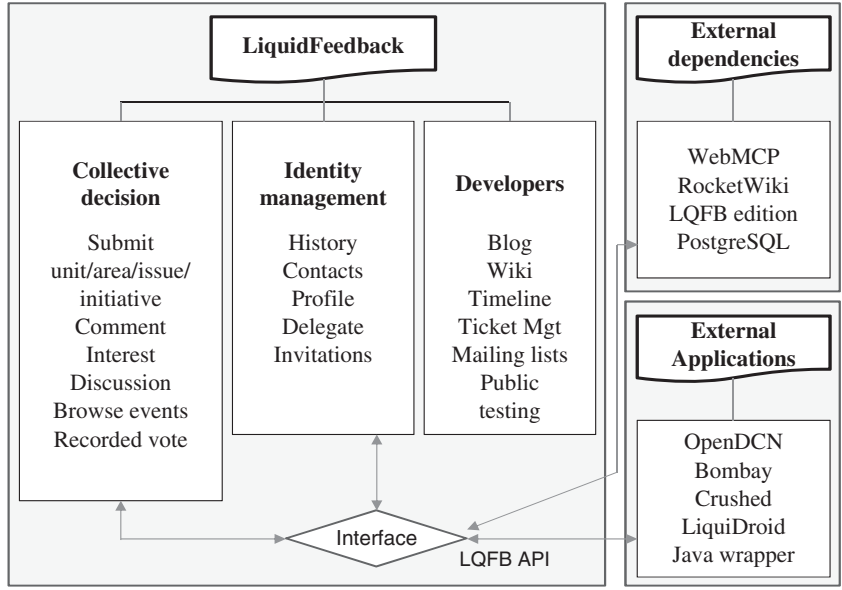

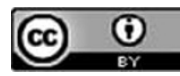

This work is licensed under a Creative Commons Attribution 3.0 Unported License. The images or other third party material in this article are included in the article's Creative Commons license, unless indicated otherwise in the credit line; if the material is not included under the Creative Commons license, users will need to obtain permission from the license holder to reproduce the material. To view a copy of this license, visit http://creativecommons. org/licenses/by/3.0/

Figure B3 The liquidfeedback architecture. 